DOI: 10.1515/ausp-2015-0010

\title{
Interpretation - Artistic Reproduction - Translatability. Theoretical Queries
}

\author{
Judit PIELDNER \\ Sapientia Hungarian University of Transylvania (Miercurea Ciuc, Romania) \\ Department of Humanities \\ juditpieldner@yahoo.com
}

\begin{abstract}
Along Wolfgang Iser's considerations-formulated in his work entitled The Range of Interpretation-we can speakabout translation whenever a shift of levels/registers takes place. Literary interpretation is essentially an act of translation. As Iser points out, the register to which interpretation translates always depends on the subject matter that is translated. Translation does not repeat its subject matter, making it redundant, but transposes it into another register while the subject matter itself is also tailored by the interpretive register. The presentation aims to discuss the question of translatability in relation to the hermeneutical concept of application, and proposes to rethink the issue of change of the medium of artistic expression in the light of the concept of artistic reproduction as posited by Hans-Georg Gadamer's hermeneutics in his seminal work Truth and Method.
\end{abstract}

Keywords: translatability, untranslatability, cultural and medial translation, hermeneutics

\section{Introduction}

When considering translation, we must indispensably start from the recognition of the diversity and complexity of the act of translation. The act of translation is present in the relationship between theory and practice; in this case we speak of application, putting into practice. It is also present in the interaction between different cultures; between the literal and the metaphorical; between word and image; between text and interpretation. From among this set of issues the present paper will touch, within the confines of a theoretical argumentation, upon the notion of application, the relationship between application and translation, (medial) translatability and untranslatability as well as the hermeneutical significance of artistic reproduction.

In the first part of the paper, relying on the wider sense of cultural translation and relating it to the experience of reception, I will discuss the hermeneutical 
correlation between interpretation and translation, based on Hans-Georg Gadamer's and Wolfgang Iser's concepts. The question leading to the next phase of the argumentation is how understanding works in the case of medial translation, particularly of the translation from the domain of the verbal to that of the visual. The second part of the article offers hermeneutical possibilities of answering this question, along the recognition of consubstantiality of artistic reproduction and interpretation.

\section{Interpretation as Act of Translation}

In his seminal work entitled Truth and Method Hans-Georg Gadamer dedicates a whole subchapter to the issue of application, with the title The recovery of the fundamental hermeneutic problem (Gadamer 2004, 305-336). He starts from the recognition that application, that is, the term subtilitas applicandi of traditional hermeneutics, became undeservedly marginalized in the hermeneutical process, as compared to understanding (subtilitas intelligendi) and interpretation (subtilitas explicandi). Contrary to the previous conception, Gadamer posits application not as an additional phase, but rather as the central issue of hermeneutics, and regards it as the integral part of the hermeneutical process. Application necessarily brings into discussion the act of translation. In Gadamer's definition, the notion of application means that the interpreter applies the text to his own situation. Application, that is, applying the meaning of the text to the concrete situation, is similar to the interpreter's task. The interpreter is in an intermediary and at the same time privileged situation:

But even today it is still the case that an interpreter's task is not simply to repeat what one of the partners says in the discussion he is translating, but to express what is said in the way that seems most appropriate to him, considering the real situation of the dialogue, which only he knows, since he alone knows both languages being used in the discussion. (Gadamer 2004, 307)

Thus, translating the text onto the reader's concrete situation is a constitutive moment of actual understanding, and takes place in accordance with the text's demand. Application, Gadamer writes, occurs in every act of reading, it can be found in all forms of understanding. Interpretation is, similarly, always application, thus it is always translation. This is made inevitable by being situated within tradition. This implies that Gadamer's notion of application also transmits the idea that translation always takes place in a changing situation. The historicity of transmission will inevitably result in the fact that translation will always change as compared to the previous one in accordance with this $x$ parameter. 
Thus understanding never takes place twice in the same way, the relationship to tradition cannot be the same due to the historicity of understanding.

The fact that Gadamer reconsiders and posits as of central importance an earlier ignored aspect, regarded as ex post, insignificant and occasional, is not far from Walter Benjamin's translation concept; Benjamin also considers translation of key importance, as being more significant than an aleatory operation, attached to the text ex post. Walter Benjamin writes:

Translation is properly essential to certain works: this does not mean that their translation is essential for themselves, but rather that a specific significance inherent in the original texts expresses itself in their translatability. It is clear that a translation, no matter how good, cannot have any significance for the original. Nevertheless, it stands in the closest connection with the original by virtue of the latter's translatability. (Benjamin 1997, 153)

Although in his writing The Translator's Task Walter Benjamin formulates a statement that radically contradicts reception theory, which can make the connection between his and Gadamer's concept questionable, still, it is worth thinking about the chiastic symmetry that can be discovered with the two authors: while Gadamer speaks about the act of translation present in reading, Benjamin reflects on the act of reading present in translation. The act of translation present in the hermeneutical concept of application reconsidered by Gadamer as well as the critical aspect reinforced in the act of translation in Benjamin's concept turn our attention to the interdependence of reading/interpretation and translation.

The history of interpretation, the changeability of the modes of interpretation testify that the act and working of interpretation is not at all self-evident or given. In his work entitled The Range of Interpretation Wolfgang Iser surveys the various interpretives at the level of science theory and interdisciplinarity. He considers that what is common in these practices is that they can all be conceived as activities of translation, during which the transfer from one system, register or discourse into another takes place. Iser speaks about the liminal space between the subject matter and the act of interpretation, which makes transposition necessary and problematic at the same time: the liminal space created in/by the act of translation is "bound to contain a resistance to translation, a resistance, however, that energizes the drive to overcome it." (Iser 2000, 6)

Iser's key statement is that the register into which interpretation translates always depends on what is translated. Translation is dually coded: on the one hand, according to the "viewpoints and assumptions that provide the angle from which the subject matter is approached," and according to "the parameters into which the subject matter is to be translated for the sake of grasping," on 
the other (ibid.). In the sense of this dual codedness translation does not repeat and thus makes the subject matter redundant but transposes it into another register while the register itself is modified. As Iser points out: "Whenever we translate something to something else, the register is nothing but the bootstraps by which we pull ourselves up toward comprehension." (ibid.) According to Iser, translatability depends on what kind of register is to be translated: texts, nontextual cultural phenomena or even incommensurabilities beyond language (e.g., when God is to be translated into knowledge).

According to Iser the liminal space can be bridged, and this lies not in the explanatory but in the event-like character of interpretation. The difference between interpretation as explanation and interpretation as event lies in the fact that the explanation is valid within a certain referential framework, while the performative act creates its own rules. The possibility of bridging the liminal space is thus made possible by its own performativity: something happens in interpretation, or rather we expect something to happen in interpretation. In this sense, interpretation as an act of translation, is a determining human feature, an anthropological necessity.

\section{The change of the medium of artistic expression and translatability}

Human culture is characterized by the conflict between the impossibility and necessity of translation. Or in other words, by the tension between the theory of untranslatability and the practice of translatability, about which Mihály SzegedyMaszák writes:

Translation is the most impossible possibility. On the one hand, it separates the signifier and the signified, the sound or letter and the meaning, and this is impossible almost in the same way as to transform a painting into sculpture, pentatonic music into heptatonic one, as the structure of the signifier in the original text-the system of internal repetitions, the rhyme, the wordplay, the rhythm, the sentence structure-calls forth a meaning that vanishes together with this structure; on the other hand, translation is the indispensable and unalienable component of the mode of existence of literature, with an ever growing significance in the unifying world. (Szegedy-Maszák 2008, 16, translated by me, J. P.)

The idea of untranslatability is also present in Walter Benjamin's term in the German original, Aufgabe: translation is not only a task that has to be performed, but it is at the same time also an impossible enterprise that one must sooner or later give up. 
Iser also relates the questions of cultural translation to nontextual aspects of culture:

If something nontextual, open-ended, or, beyond the reach of one's stance has to be made manageable, the hermeneutic circle may no longer be adequate. Translating open-endedness into graspability, or entropy into control, is different from translating a text into understanding, or from turning understanding into its application, or from deciphering what its disguises may either hide or reveal. (Iser 2000, 8)

The paradox of (un)translatability also characterizes the discourse of medial translation. Iser reflects on the modes of transforming incongruences into congruences; the hermeneutical issues, also pertaining to general science theory, can also be applied to the particular case of medial translation.

In his volume Aufschreibesysteme 1800-1900 Friedrich A. Kittler formulates the idea that ever since the film medium was born, the criterion of high literature has been the impossibility of turning it into the screen (Kittler 1995, 314). Kittler's statement seems to be consonant with Dezső Kosztolányi's translation theory-embedded in his organic view of language-according to which there are different degrees of transferability from one language into another, and the more developed a language, the less it can be translated. In one of his essays on translation Kosztolányi radically formulates this idea: "It is not possible to translate.” (Kosztolányi 1990, 120)

In another writing of his Kosztolányi expounds on how he actually understands his statement quoted above:

If we admit the justifiedness of literary translation, then we cannot claim fidelity from the translator, as fidelity to the letter is infidelity. The material of each language is different. The sculptor carries out his task differently depending on whether he has to mould a figure from marble or from wood. Materiality imposes on him the must to change; there are always two that work on the sculpture: the sculptor and the matter itself. The translator's work is similar to this. He has to carve a sculpture from a totally different material. This needs freedom. A poem must be translated with the precision of a chartered interpreter to the same little extent as wordplay. A new one, another one must be created, which is identical with the original in spirit, in music, in form; which is false but still true. To translate a literary text is to dance bound hand and foot." (Kosztolányi 1990, 575-576, translated by me, emphasis mine, J. P.) ${ }^{1}$ 
Kosztolányi's view on translation is related to the romantic tradition of creative freedom. He recognizes that fidelity to the letter is mere illusion. Due to the determining character of the materiality of language the experience of being preceded by language refers to translation to the same extent as it refers to writing itself. Language, the material of the literary work, must not be thought of as an external aspect, language is not "vesture" ["köntös"], but "body itself," "shell" and "kernel" together, Kosztolányi writes $(1990,167)$.

The impossibility of turning literature into screen as well as the impossibility of translation equally refer to the same operation of re-producing the original-in another medium, in another language. Béla Balázs relates the difficulties and problems of adaptation to "the inner structure of film essence." He reveals the paradox that the literary texts characterized by excessive visuality constitute the greatest challenge for adaptation. The more organic the interrelatedness of the story skeleton and the visuality of the text, the more problematic it is for the film to render it adequately. He expresses this view-which will be the basis of the semiotic approach-in a set of suggestive metaphors: the camera transilluminates the literary works as a Roentgen ray, and shows the skeleton of the plot, which is no longer literature and not yet film, but the content that is the essence of neither of the two (cf. Balázs 1984, 33).

The most frequent question of the specialist literature dealing with medial translation refers to whether medial commensurability is possible, whether it is possible to create equivalences through which the systematic replacement of verbal signifiers with visual signifiers can be carried out. How can the specifically literary be transformed, "translated" into the specifically cinematic, from one system of signifiers into the other? The question can be answered differently in the light of distinct theoretical approaches.

According to semiotics-based views, while the materiality of literature differs from that of film, at the level of the deep structure of narrative they share common grounds. Their relationship is described as code transfer, in the sense that, though words and images belong to distinct sign systems, at a certain level of abstraction they share common-narrative, perceptual, referential, symboliccodes, which make the transformation, the comparison possible and provide solid medial links between the two media (Cohen 1979). Theories relying on the basic premise of semiotics outlined above take into account the similarities and differences of film and literature, focusing on what is common and, respectively, what is medium-specific in the two of them. Due to the differences of the two media, the task of medial translation is thus to find an aesthetic equivalent appropriate to literary texts. 


\section{The hermeneutical significance of artistic reproduction}

According to the assumptions of the hermeneutics of the image, we get to a deeper understanding of visual artworks relying on texts downright by suspending the principle of adequation. As the aim is not to dissolve the (aesthetic, historical, medial) distance that is created with the act of transposition, it is the very resistance implied in the distance that activates the intention of interpretation. The distance created in the incongruencies between the text and the image indicates the direction of interpretation, providing the necessary perspective for a productive interpretation.

The issue of the relationship between texts and images is considered by András Rényi as "the eminent problem of the hermeneutics of the image" (Rényi 1999, 66, translated by me, J. P.), as long as the translation of a text into the language of the image is not considered as a task that can be performed along well-formed preconceptions, but rather as one that always creates a new situation for both the creator and the receiver. The connections, the passages between texts and images constitute a recurrent issue in the tradition of art history, let us think of the principle of ut pictura poesis resounding in the present ever since the antiquity, formulating the idea of commensurability of poetry and painting; or let us think of the term invention in the context of painting, which in the tradition of iconology refers to finding the adequate visual equivalent of the notions or texts to be represented.

These examples taken from the history of aesthetics can be related to film, the (relatively) new branch of art. The visual "reproduction" of a literary text is in strong connection with the literary text, however, it distances the receiver from the materiality of the letter. Through the change of the medium of artistic expression the written text is simultaneously present (in praesentia), as constitutive part of the integrative intermedial character of film, and absent (in absentia), as a distant reference. The hermeneutical experience is based on the recognition of the simultaneous presence and mutual interdependence, still incommensurability of text and image. (Cinematic) interpretation is a possible rewriting of the literary text, a reconfiguration of the meanings of the literary text; a special relationship is formed in which text and image mutually overwrite and interpret each other.

The insights of Gadamer's philosophical hermeneutics can bring us closer to the essence of the set of questions presented above. The screen adaptation, or the translation of the eminent literary text, in Gadamer's sense of the term, into the language of film, seems to be doomed to failure from the outset, due to the very mode of existence and characteristic features of the eminent text. As in the case of eminent texts, we can speak of the total equivalence of form and content, the what and the how inseparably layer upon each other: "Such a text fixes the pure speech act and therefore has an eminent relation to writing. In it language is present in such a way that its cognitive relation to the given disappears, just as does the communicative relation to the addressee." (Gadamer 2004, 578) 
Through its linguistic constitutedness the eminent text carries an infinite potential of meanings; through this inherent abundance in meanings it is capable of addressing the reader and of offering a distinct set of meanings on the occasion of each encounter with the text. The eminent text is capable of saying more than what it literally expresses, it is also capable of expressing what its letters do not utter. The eminent text is not subjected to the laws of time, as once read it becomes inalienable part of the present of reading.

Several examples may justify that it makes indeed no sense to call film to account for the compositional, poetical and rhetorical unity of literature, its unrepeatable uniqueness inseparable from its materiality. The-theatrical, cinematic, musical-reproduction of the eminent text aims at, or rather is constrained to, concretization, it bears the risk of being capable of "reproducing" only one meaning —or a limited number of meanings-, while the rest of meanings goes unrecognized; thus we necessarily have the impression that artistic "reproduction" is poorer than the "original" and we are compelled to resort to the rhetoric of gain or loss in interpretation.

However, the mode of existence of the eminent text also makes possible that its reproduction, as a possible interpretation, becomes itself an eminent text, capable of generating additional meanings, even if not in an identical manner. Gadamer restores the significance of reproduction, as what "is not a second creation re-creating the first; rather, it makes the work of art appear as itself for the first time." (Gadamer 2004, 400) Accordingly, reproductive interpretation and philological interpretation are based on the same premise, that of translation, thus they are consubstantial, it is of no conceptual significance to make a distinction between them.

Retrieving the hermeneutical significance of reproduction is based on the fact that the artwork is essentially dependent on presentation, and it can preserve its identity even if the presentation radically transforms, distorts the artwork. The concept of reproduction is in relation with non-identical repetition, and is to be understood as such. In Gadamer's words, "Here 'repetition' does not mean that something is literally repeated-i.e., can be reduced to something original. Rather, every repetition is as original as the work itself." (Gadamer 2004, 120) Artistic reproduction, as interpretation, disposes in itself of the quality of creation, "bringing forth."

Gadamer illuminates the essential interdependence and ontological interwovenness of the "original" and its "reproduction" through the difference between picture (Bild, also image) and copy (Abbild). While the copy (Abbild) fulfils its role if we can recognize the model, the represented without difficulty, the picture (Bild) does not direct our attention further to the represented, as representation itself is what deserves attention, "picture has an essential relation to its original." (Gadamer 2004, 132) Presentation [Darstellung] essentially belongs to the presented artwork, revealing its unalienable aesthetic truth. 
Thus, presentation [Darstellung] is not accidental to the artwork, on the contrary, it constitutes the mode of existence of the artwork and thus has to be understood in an ontological sense. In his aesthetic and hermeneutical conclusions regarding the interpretation of the concept of the play as the mode of existence of the artwork, as "transformation into structure," being in an essential relation to self-presentation [Selbstdarstellung], Gadamer reveals the significance of presentation as follows:

The world that appears in the play of presentation does not stand like a copy next to the real world, but is that world in the heightened truth of its being. And certainly reproduction-e.g., performance on the stage- is not a copy beside which the original performance of the drama itself retains a separate existence. (...) Hence, in presentation, the presence of what is presented reaches its consummation. (Gadamer 2004, 132-133)

As a conclusion, by suspending the principle of equivalence, the dichotomy and hierarchy of the original and the copy, untranslatability can be turned from loss into gain in the experience of-or rather in between-arts and media; it is the non-identical that will provide space for interpreting the differences and displacements, resulting in a fruitful dialogue between the self and the other.

\section{Works cited}

Balázs Béla. 1984. A látható ember. A film szelleme. [Visible Man. The Spirit of Film.] Budapest: Gondolat.

Benjamin, Walter. The Translator's Task. Translated by Steven Rendall. TTR no. 2: 151-165.

Cohen, Keith. 1979. Film and Fiction. The Dynamics of Exchange. New Haven: Yale University Press.

Gadamer, Hans-Georg. 2004 [1960]. Truth and Method. Second, Revised edition.

Translated by Joel Weinsheimer and Donald G. Marshall. London and New York: Continuum.

Iser, Wolfgang. 2000. The Range of Interpretation. Columbia University Press.

Kittler, Friedrich A. 1995. Aufschreibesysteme 1800-1900. München: Wilhelm Fink Verlag.

Kosztolányi Dezső. 1990. Nyelv és lélek. [Language and Soul.] Budapest: Szépirodalmi.

Rényi András. 1999. A testek világlása. Hermeneutikai tanulmányok. [The Gleaming of Bodies. Hermeneutical Studies.] Budapest: Kijárat.

Szegedy-Maszák Mihály. 2008. Megértés, fordítás, kánon. [Understanding, Translation, Canon.] Bratislava: Kalligram. 